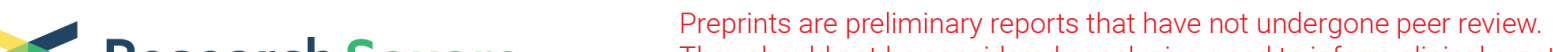

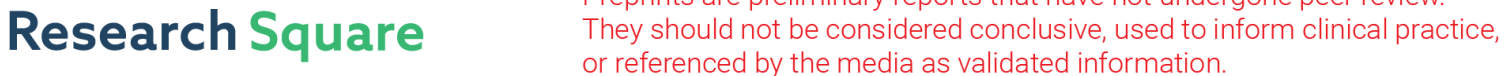

\section{Toxicity and Efficacy of Stereotactic Body Radiotherapy for Ultra-central Lung Tumours: a Single Institution Real Life Experience}

Elodie GUILLAUME

Institut de Cancérologie de la Loire: Institut de Cancerologie de la Loire

Ronan TANGUY

Centre Léon Bérard: Centre Leon Berard

Myriam AYADI

Centre Léon Bérard: Centre Leon Berard

Line CLAUDE

Centre Leon Berard

Coralie MONCHARMONT

Centre Léon Bérard: Centre Leon Berard

Nicolas MAGNE ( $\square$ nicolas.magne@icloire.fr)

Institut de Cancerologie de la Loire

Isabelle Martel-Lafay

Centre Léon Bérard: Centre Leon Berard

\section{Research Article}

Keywords: Stereotactic body radiotherapy, ultra-central lung tumours, NSCLC, metastases

Posted Date: March 15th, 2021

DOl: https://doi.org/10.21203/rs.3.rs-296037/v1

License: (9) This work is licensed under a Creative Commons Attribution 4.0 International License.

Read Full License

Version of Record: A version of this preprint was published at The British Journal of Radiology on November 19th, 2021. See the published version at https://doi.org/10.1259/bjr.20210533. 


\section{Abstract}

Purpose: The use of stereotactic body radiotherapy (SBRT) to treat ultra-central lung tumours remains more controversial than for peripheral and central tumours. We carried out a study about SBRT in patients with ultra-central lung tumours treated in our Cancer Centre. Our objectives were to assess toxicities, local control (LC) rate and survival data.

Methods: We conducted a retrospective and monocentric study about 74 patients with an ultra-central lung tumour, consecutively treated between 2012 and 2018. Ultra-central tumours were defined as tumours whose PTV (planning target volume) overlapped one of the following organs at risk (OAR): the trachea, right and left main bronchi, intermediate bronchus, lobe bronchi, oesophagus, heart. Patients with primary or secondary tumour were enrolled in the study.

Results: Median follow-up was 25 months. Two patients (2.7\%) showed grade 3 toxicity. No grade 4 or 5 toxicity was observed. Eleven per cent of patients experienced primary local relapse. Local control rate was $96.7 \%$ at 1 year and $87.6 \%$ at 2 years. Median progression free survival (PFS) was 12 months. Median overall survival (OS) was 31 months.

Conclusions: SBRT for ultra-central tumours remains safe and effective. Thus, SBRT can be considered to be well tolerated as long as protecting organs at risk remains treatment planning priority. Besides, as the results of ongoing prospective trial have not been published yet, SBRT for ultra-central tumours should be performed with caution.

\section{Introduction}

Stereotactic body radiotherapy (SBRT) has become the standard of care for inoperable, early-stage nonsmall cell lung cancers (NSCLC) [1-3]. It is also used for inoperable pulmonary metastases in case of controlled oligometastatic disease [4]. SBRT definitely has a positive efficacy/toxicity ratio for peripheral lung tumours [5]. Yet, this was counterbalanced by a prospective study by Timmerman et al. showing that using the same 3 fractions schedule for central tumours caused more toxicities than for peripheral tumours. Indeed, 2-years' survival with no grade $\geq 3$ toxicity was $54 \%$ in the central tumours group vs $83 \%$ in the peripheral tumours group [6]. Importantly, the RTOG 0813 trial defined central lesions as tumours contacting or overlapping a $2 \mathrm{~cm}$ zone around the proximal bronchial tree (carina, right and left main bronchi, intermediate bronchus and lobe bronchi) as well as tumours directly adjacent to the mediastinal pleura. In case of a 5 -fractions dose escalation, $12 \mathrm{~Gy} /$ fraction was the highest tolerated dose and grade $\geq 3$ toxicity was likely to be $7.2 \%$. Local control (LC) rate at 2 years was $87.9 \%$ in the $12 \mathrm{~Gy} /$ fraction group [7]. Treatment in 5 fractions seems to be better adapted to central lesions regarding toxicity and efficacy.

The use of SBRT for ultra-central tumours remains more controversial than for peripheral and central tumours. Some studies pointed out a higher risk of toxicity and a lower local control rate [8,9], mainly due to the proximity of organs at risk (OAR). Moreover, the definition of ultra-central tumours fails to win unanimous support [10-12], about 12 definitions can be found in literature (tumour or planning target 
volume (PTV) directly contacting the proximal bronchial tree and even the trachea, oesophagus, pulmonary vessels and heart). In 2015, Chaudhuri et al. were the first to specifically study ultra-central tumours. They defined them as tumours directly overlapping the trachea or the proximal bronchial tree [10]. For other studies they are tumours contacting the proximal bronchial tree only $[9,13]$. Conversely, other reports add tumours whose PTV contact with the oesophagus or the pulmonary vein or artery [12, 14]. Finally, some authors include tumours contacting with the pericardium or the heart [15].

The present study is one the rare studies exclusively dedicated to ultra-central locations. The main objectives of the study were to assess grade $\geq 3$ toxicities, local control (LC) rate, survival data and dosimetric considerations.

\section{Materials And Methods}

\section{Patients' characteristics}

We carried out a retrospective study about all consecutive patients with an ultra-central pulmonary tumour. All patients were treated with SBRT in a unique Cancer Centre (Léon Bérard Cancer Centre Radiotherapy Department, Lyon, France) between January 2012 and December 2018. Patients' selection is detailed in the flow chart (Fig. 1). The study was registered in compliance with the General Data Protection Regulation (GDPR) under the number R201-004-045. All patients provided informed consent. Patients treated with SBRT for any ultra-central lesion were included - whether primary, secondary, parenchymal or nodal (mediastinal or hilar). Patients were accrued only in case of biopsy-confirmed disease or in case of hyper metabolic suspiciously growing lesion visible on the positron emission tomography (PET) scan.

\section{Tumour location definition}

Ultra-central tumours were defined as tumours whose PTV overlapped one of the following organs at risk: the trachea, right and left main bronchi, intermediate bronchus, lobe bronchi, oesophagus, heart. We did not include mediastinal vessels as their dose constraints are easily respectable unlike those of the main bronchi and oesophagus.

\section{SBRT technique}

\section{- Machines}

Depending on machine implementation, treatment was delivered on 3 different machines namely CyberKnife ${ }^{\circledR}$ (Accuray Sunnyvale, USA), Synergy ${ }^{\circledR}$ (Elekta, Stockholm, Sweden) and Versa HD® (Elekta, Stockholm, Sweden). The possibility or not for the Cyberknife ${ }^{\circledR}$ to track the tumour motion real-time because of its location and size justified the change of machine. Thus, some treatments were delivered on different machines. 
Simulation CT scans were performed on a Philips Brillance Big Bore® (Philips Healthcare, Cleveland, USA). A 4D CT scan associated with respiration was obtained for parenchymal lesions, without intravenous contrast injection. A 3D CT scan was obtained after IV injection for mediastinal and hilar tumours with a $2 \mathrm{~mm}$ slice thickness. Radiation total dose was delivered in 5 to 10 fractions in $4.5 \mathrm{~Gy}$ to 10 Gy per fraction. Each fraction was delivered every 2 days.

PTV was usually obtained after a $5 \mathrm{~mm}$ margin was added to the GTV or ITV. Delineated OAR were the trachea, right and left main bronchi, intermediate bronchus, lobe bronchi, lungs, oesophagus, heart (pericardium included) and the medullary canal. Isodose covering PTV (often $80 \%$ isodose) was used for the treatment prescription. OAR constraints were the same as those from Timmerman et al. in 2008 [16], EORTC LungTech [17] and RTOG 0813 [7] trials. When necessary, PTV was underdosed to protect OAR. Dosimetric parameters for each OAR were maximal dose $\left(D_{\max }\right)$ except for homolateral lung for which it was median dose $\left(D_{\text {med }}\right)$.

\section{Follow-up}

Patients were followed every 3 months for the first 2 years and every 6 months thereafter. The radiation oncologists graded radiation induced toxicities using the Common Terminology Criteria for Adverse Events (CTCAE), version 4.0. Regarding radiation pneumonitis, only symptomatic pneumonitis were taken into account. Toxicities occurring between 0 to 90 days after radiotherapy were considered as acute. Those occurring after 90 days were regarded as late toxicities. Patients were assessed by chest, abdomen and pelvis CT scan and brain imaging (MRI or CT). PET CT scan was optional. Tumour response was evaluated according to the RECIST criteria (Response Evaluation Criteria in Solid Tumours, version 1.1). Local relapse was defined as recurrence in the irradiated site, and regional relapse as mediastinal and ipsilateral lung recurrence.

\section{Statistical analysis}

Descriptive statistics were calculated and presented as frequency, percentage and median values (minimum, maximum). Follow-up duration was calculated from the 1st day of SBRT and the most recent follow-up or death. The events of interest to calculate LC and progression free survival (PFS) rates were the date of the first recurrence (local on the irradiated site, regional, metastatic) and the date of the first metastatic recurrence (in case of non-primary metastatic relapse). Last follow-up update was May 2020. Estimates for Overall Survival (OS), PFS and LC rates were calculated using the Kaplan-Meier method and univariate tests used the Log-rank test. For the statistical analysis, some continuous variables (biologically effective dose with $\alpha / \beta=10\left(B E D_{10}\right)$ ) were determined by significant clinical data. Fisher's exact test was carried out for univariate analyses of qualitative variables using contingency tables.

In order to compare data about the different treatment plans, tumours $\mathrm{BED}_{10}$ were calculated to compare doses in different fractionations. Dosimetric parameters for target volumes were the different $\mathrm{BED}_{10}$ : minimum $\left(D_{\text {min }}\right)$, maximum $\left(D_{\text {max }}\right)$, median, $\left(D_{\text {med }}\right)$, received by $1 \%$ of the PTV $\left(D_{1 \%}\right)$ and received by $98 \%$ 
of the PTV $\left(D_{98 \%}\right)$, as well as the average between $D_{1 \%}$ and $D_{98 \%}$. The 2 Gy per fraction equivalent dose (EQD2) for OAR was calculated.

Data were analysed using a SPSS v20.0 software. P-value $<0.05$ was considered to represent statistical significance.

\section{Results}

\section{Patient and tumour characteristics}

Seventy-four patients with ultra-central lung tumours treated with SBRT were retrospectively studied. They accounted for $4.4 \%$ of the 1702 lung SBRT treated in our Centre. Patient and tumour characteristics are provided in Table 1. Patient median age was 69 years old; $46 \%$ of them were at least 70 years old.

\section{Treatments}

Treatment characteristics are summarized in Table 2. PTV overlapped the right and left main bronchi or intermediate bronchus or lobe bronchi ( $50 \%$ of cases), the heart $(40.5 \%)$, the trachea $(13.5 \%)$ and the oesophagus (10.8\%).

Treatments were performed on the CyberKnife $\AA$, the VersaHD $\AA$ and the Synergy ${ }^{\circledR}$ for 52 patients (70.3\%), 14 patients $(18.9 \%)$ and 8 patients $(10.8 \%)$, respectively. Several fractionation schedules were prescribed. $50 \mathrm{~Gy}$ in 5 fractions of $10 \mathrm{~Gy}$ was mostly used (32.4\%), then $40 \mathrm{~Gy}$ in 5 fractions of $8 \mathrm{~Gy}$ (17.6\%), $45 \mathrm{~Gy}$ in 5 fractions of $9 \mathrm{~Gy}(10.8 \%)$. Median prescribed $\mathrm{BED}_{10}$ was $82 \mathrm{~Gy}$ and $\mathrm{BED}_{10}$ was $\geq 100$ Gy in $37.8 \%$ of treatments. Prescription isodose ranged from $78-82 \%$ for most treatments $(93.2 \%)$.

\section{Dosimetry}

Dosimetric parameters are listed in Table 3. Median GTV BED 10 was 99 Gy.

\section{Toxicities}

Acute toxicities are described in Table 4. Forty-four patients out of 74 (59.5\%) experienced no toxicity. Thirty-two grade 1 toxicities were reported. Two patients (2.7\%) had grade 3 toxicities: 1 pneumonitis and 1 oesophagitis. Clinical cases corresponding to theses toxicities are detailed in Table 5. No patient experienced grade 4 or 5 toxicities. Fatigue was the most commonly toxicity: $27.1 \%(n=20)$ of patients (grade 1 and/or 2). Median time to acute toxicities occurrence was 11 days (range 5-81).

Four acute oesophagitis were reported; PTV overlapped or contacted with either oesophagus (3 patients) or trachea (1 patient) in all those cases. When PTV overlapped or contacted with oesophagus, oesophagitis were recurrent $(p=0.007)$ and of higher grade $(p=0.004)$. Oesophagitis were also more common when $D_{\max }$ to oesophagus was $>50$ Gy in $\operatorname{EQD2}(\alpha / \beta=3)(p=0.005)$. A $D_{\max }$ to oesophagus in EQD2 $(\alpha / \beta=3)>64$ Gy $\left(D_{\max }\right.$ accepted in LungTech trial [17]) was linked with oesophagitis $(p=0.009)$ 
and with higher-grade oesophageal toxicity $(p=0.005)$. Only one grade 3 oesophagitis was reported, 11 days after the start of SBRT: PTV overlapped with oesophagus and $D_{\max }$ oesophagus was $64.1 \mathrm{~Gy}$ (EQD2) for a prescribed dose of $50 \mathrm{~Gy}$ in 5 fractions on $80 \%$ isodose line.

Patients whose PTV overlapped or contacted with the heart experienced more acute lung toxicities $(p=$ $0.014)$ and more coughing $(p=0.024)$. There was no correlation between dosimetric parameters regarding the heart, bronchi, trachea, homolateral lung and acute lung toxicities. There was only one grade 3 lung toxicity, which could be radiotherapy-induced. Indeed, the patient experienced some symptoms of pneumonitis but no fever or inflammatory syndrome. Besides, images showed possible radiation-induced lung injury. It appeared 42 days post radiation in an 83-year-old patient with a medical history of chronic respiratory failure requiring home oxygen. He had to be hospitalized and fully recovered from pneumonia.

Grade 1 dermatitis was the sole reported late toxicity (1.4\%), it was observed 10 months after SBRT start.

\section{Efficacy}

Median follow-up was 25 months (range: $3-86)$. At last follow-up, $31.1 \%(n=23)$ of the patients were alive and $5.4 \%(n=4)$ of the patients were lost to follow-up.

At a 7-month median time (range: 1-17), 8 patients (10.8\%) had primary local relapse. They first relapsed in the irradiated site either before or concurrently to regional and/or metastatic recurrence. Four patients (5.4\%) had an isolated primary local relapse and 4 others experienced local and regional and/or metastatic primary relapse. At 1 and 2 years, primary local control rates were $96.7 \%$ and $87.6 \%$, respectively. LC rate did not differ between patients with localised cancer and those with metastatic cancer (or localised relapse). The type of OAR overlapping with PTV made no difference. Patients treated with PTV prescribed $\mathrm{BED}_{10}<50$ Gy experienced more primary local relapses $(p=0.002)$. When treatment was delivered with PTV prescribed $\mathrm{BED}_{10}$ at $60,70,90$ or $100 \mathrm{~Gy}$, no difference was evidenced. Local recurrences were more common with GTV receiving $D_{\min } B_{10}<50$ Gy $(p=0.002)$. No correlation was found between local control rate and the following doses to GTV $\left(B D_{10}\right)$ : mean, median and maximum doses. Similarly, no correlation was observed between $L C$ rate and dosimetry doses to PTV $\left(B E D_{10}\right): D_{1 \%}$, $D_{98 \%}, D_{\text {ave }}$ (between $D_{98 \%}$ and $D_{1 \%}$ ) or between LC rate and PTV coverage, GTV volume, and PTV volume. Regarding the 4 isolated local primary relapses, they were correlated with a Paddick conformity index $\leq$ $0.8(p=0.042)$.

Twelve patients (16.2\%) presented with primary regional recurrence, $8(66.7 \%)$ of them had an isolated regional recurrence. The risk of regional recurrence was higher in patients with localised relapse than in those with localised or metastatic disease $(p=0.007)$. The risk of regional recurrence was higher if local relapse occurred during follow-up $(p=0.004)$.

Forty-one patients (55.4\%) had metastatic recurrence. For 32 of them $(78 \%)$ it was their first recurrence after SBRT whereas for the 9 others (22\%) it occurred after local and/or regional relapse. 
Median PFS was 12 months (95\% Cl: 5-20). PFS at 1 and 2 years were $51.2 \%$ (95\% Cl: $45.2-57.2)$ and $35 \%$ (95\% Cl: $28.9-41.1)$, respectively. By the end of the study, 47 patients had relapsed (63.5\%). Median OS was 31 months (95\% Cl: $23-39)$. OS were $86.2 \%(95 \% \mathrm{Cl}: 82.1-90.3)$ at 1 year and $61.2 \%(95 \% \mathrm{Cl}$ : 55.3-67.1) at 2 years. Median age of death was 70 years old (range: 20-93). There was no difference between the median OS of patients with primary localised tumour (32 months) (95\% Cl: 19-46) and patients with localised recurrence or metastases (31 months) (95\% Cl: 25-37). Patients with metastatic relapse after SBRT had a lower OS $(p=0.044)$.

\section{Discussion}

The present study is one of the rare to describe exclusively ultra-central tumours through real life observational case reports. The 74 patients who were included represent a very low number of patients $(4.4 \%)$ in view of the 1702 SBRT procedures for lung tumours in our Cancer Centre. In literature, dedicated data remains scarce and insufficiently reported. Few patients experienced grade $\geq 3$ toxicities $(2.7 \%)$ and none had grade 5. Local control was $96.7 \%$ at one year and $87.6 \%$ at 2 years. Median OS was 31 months.

As this kind of location remains uncommon, few significant articles can be found in literature. All the studies about ultra-central lung tumours treated with SBRT are retrospective and include no more than one hundred patients. Globally, literature analysis reveals a large heterogeneity in ultra-central lung tumours definition, prescribed dose, number of fractions. Indeed, the prescribed dose was usually either $50 \mathrm{~Gy}$ or $60 \mathrm{~Gy}$, delivered with 5 to 15 fractions of 5 to $12 \mathrm{~Gy}[10,13,18]$. The $\mathrm{BED}_{10}$ ranged from 75 to $132 \mathrm{~Gy}$. The most commonly described SBRT schedule for ultra-central tumours was 60 Gy in 8 fractions of $7.5 \mathrm{~Gy}[14,15]$. In our study, we mostly used 5 fractions ( $68.9 \%$ of treatments). When OAR dose constraints could not be respected, the radiation oncologist changed for $8(12.2 \%$ of cases) or $10(9.5 \%)$ fractions.

In the present study, $2.7 \%(n=2)$ of patients experienced grade $\geq 3$ toxicities, without toxicity-related death. $\mathrm{BED}_{10}$ was $<100 \mathrm{~Gy}$ in $62.2 \%$ of patients. Yang et al. and Cong et al. obtained similar results for ultra-central SBRT with less than $5 \%$ of severe toxicities $[15,19]$. Other studies about ultra-central SBRT found more grade $\geq 3$ and grade 5 toxicities. Wang et al. found $22 \%$ of grade $\geq 3$ and $11 \%$ of grade 5 , with $10 \%$ of patients who received antiangiogenic agents within 90 days of SBRT [20,21]. In Tekatli et al. trial, $38 \%$ of patients had grade $\geq 3$ toxicities and $21 \%$ had grade 5 [17].

Five per cent of oesophageal toxicities were observed in our study. It was statistically significant when PTV overlapped with oesophagus volume. When $D_{\max }$ to oesophagus was > 64 Gy (EQD2) - a higher constraint than in the LungTech Trial [17]- the risk of oesophagitis was higher as well as its grade. Duijm et al. showed that meeting with usual dose constraints to oesophagus for central SBRT induced a low risk of high grade toxicity [22].

The low rate of radiation-induced pneumonitis could be explained by an homolateral lung $D_{\text {ave }}<9.14$ Gy (6 Gy in the present study) [23]. Moreover, we only focused on pneumonitis symptoms because 
radiological imaging was less clinically significant. The rate of lung toxicity was higher when PTV overlapped with the heart. In a large cohort of NSCLC patients, Tucker et al. found no evidence that incidental heart exposure during normofractionated radiotherapy had a noticeable impact on the occurrence of moderate or severe radiation-induced pneumonitis [24]. However, Wong et al. showed that bilateral ventricles $\mathrm{D}_{\max }$ was associated with poorer survival (no cancer-related death) [25].

Tumours contacting the trachea and/or the proximal bronchial tree should be regarded as ultra-central tumours and thus, dose fractionation should be adapted to avoid potential severe toxicities such as stenosis, necrosis, fistula, pulmonary haemorrhage and even pneumonitis [21]. Nevertheless, tumours whose PTV overlapped with oesophagus (1 grade 3 oesophagitis in our study) should also be taken into account, even if some trials decided against it $[13,26]$. Moreover, further investigations are required to consider tumours contacting with the heart as ultra-central tumours. Thus, limiting the definition of ultracentral tumours to those contacting with the trachea and/or the proximal bronchial tree may not be satisfactory to us.

In the present study, with a median prescribed $\mathrm{BED}_{10}=82 \mathrm{~Gy}$ and a prescribed $\mathrm{BED}_{10}<100 \mathrm{~Gy}$ for $62.2 \%$ of the lesions, a low local control rate could be expected, according to studies published about 10 years ago $[27,28]$. Moreover, the median PTV coverage was $87 \%$ and the median Paddick conformity index was 0.72. Yet, we obtained a local control rate of $96.7 \%$ at 1 year and $87.6 \%$ at 2 years; $10.8 \%$ of patients had a primary local relapse. Similar results were reported by Yang et al. and in the meta-analysis by Chen et al. $[15,29]$. In the present study, a prescribed $\mathrm{BED}_{10}<50 \mathrm{~Gy}$ was correlated with an increasing risk of local recurrence. Loi et al. found $\mathrm{BED}_{10}>75 \mathrm{~Gy}$ was associated with higher $\mathrm{LC}$ rate [14]. In a modelling study, Klement et al. showed that in lung SBRT, the following $B E D_{10}$ of PTV were predictive of LC rate: $D_{1 \%}$, prescribed dose [30]. Such a link was not found in our study but Klement's study was not specifically about ultra-central tumours.

\section{Conclusion}

To sum up, in the present study, patients treated with SBRT for ultra-central lung tumours experienced few grade 3 toxicities $(2.7 \%)$ and no grade 4 or 5 toxicities, due to the highest compliance with dose constraints to OAR. In terms of LC rate, SBRT remains efficient. Nevertheless, prospective data is lacking. Yet, the phase 3 SUNSET trial is currently ongoing and aims at determining safety of SBRT with a dose escalation design (starting dose $60 \mathrm{~Gy}$ in 8 fractions and other levels with 5, 6, 10 fractions) [31]. As long as the results of ongoing prospective trial have not been published, SBRT for ultra-central tumours should be performed with caution

\section{Declarations}

\section{Ethics approval and consent to participate}


The institutional ethics committee approved the study that was conducted in compliance with the Helsinki Declaration. The French National Agency in charge of regulating Data Protection agreed with our database.

The study was registered in compliance with the General Date Protection Regulation (GDPR) under the number R201-004-045.

All patients provided informed consent.

\section{Consent for publication}

All patients provided informed consent.

\section{Availability of data and materials}

The study was registered in compliance with the General Date Protection Regulation (GDPR) under the number R201-004-045.

\section{Competing interests}

The authors declare that they have no competing interests" in this section.

\section{Funding}

None.

\section{Authors' contributions}

EG and NM wrote the manuscript (draft and final version); RT was responsible for the statistical analysis; MY and LC were involved in the project administration; CM and IML helped with the verification part.

All authors read and approved the final manuscript.

\section{Acknowledgements}

I wish to thank Sandrine Sotton for her assistance with the English translation of this article.

I would like to thank Alexandre Munoz for his help with the use of treatment planning systems.

\section{References}

1. G. M. M. Videtic et al., « Stereotactic body radiation therapy for early-stage non-small cell lung cancer: Executive Summary of an ASTRO Evidence-Based Guideline », Practical Radiation Oncology, vol. 7, nº 5, p. 295-301, sept. 2017, doi: 10.1016/j.prro.2017.04.014. 
2. C. B. Falkson et al., " Guideline for radiotherapy with curative intent in patients with early-stage medically inoperable non-small-cell lung cancer », Curr Oncol, vol. 24, nº 1, p. e44-e49, févr. 2017, doi: 10.3747/co.24.3358.

3. R. Timmerman et al., "Stereotactic body radiation therapy for inoperable early stage lung cancer », JAMA, vol. 303, n 11, p. 1070-1076, mars 2010, doi: 10.1001/jama.2010.261.

4. J. E. Lodeweges, T. J. Klinkenberg, J. F. Ubbels, H. J. M. Groen, J. A. Langendijk, et J. Widder, « Longterm Outcome of Surgery or Stereotactic Radiotherapy for Lung Oligometastases », Journal of Thoracic Oncology, vol. 12, nº 9, p. 1442-1445, sept. 2017, doi: 10.1016/j.jtho.2017.05.015.

5. M. Guckenberger et al., "ESTRO ACROP consensus guideline on implementation and practice of stereotactic body radiotherapy for peripherally located early stage non-small cell lung cancer », Radiother Oncol, vol. 124, n 1, p. 11-17, 2017, doi: 10.1016/j.radonc.2017.05.012.

6. R. Timmerman et al., « Excessive Toxicity When Treating Central Tumors in a Phase II Study of Stereotactic Body Radiation Therapy for Medically Inoperable Early-Stage Lung Cancer ", Journal of Clinical Oncology, vol. 24, n 30, p. 4833-4839, oct. 2006, doi: 10.1200/JC0.2006.07.5937.

7. A. Bezjak et al., « Safety and Efficacy of a Five-Fraction Stereotactic Body Radiotherapy Schedule for Centrally Located Non-Small-Cell Lung Cancer: NRG Oncology/RTOG 0813 Trial », Journal of Clinical Oncology, vol. 37, n 15, p. 1316-1325, mai 2019, doi: 10.1200/JC0.18.00622.

8. M. Daly, J. Novak, et A. Monjazeb, «P2.05-056 Safety of Stereotactic Body Radiotherapy for Central, Ultracentral, and Paramediastinal Lung Tumors », Journal of Thoracic Oncology, vol. 12, $n^{\circ} 1, \mathrm{p}$. S1066, janv. 2017, doi: 10.1016/j.jtho.2016.11.1491.

9. M. Meng et al., « Risk-adapted stereotactic body radiation therapy for central and ultra-central earlystage inoperable non-small cell lung cancer », Cancer Science, vol. 110, n 11, p. 3553-3564, nov. 2019, doi: $10.1111 /$ cas. 14185 .

10. A. A. Chaudhuri et al., « Stereotactic ablative radiotherapy (SABR) for treatment of central and ultracentral lung tumors », Lung Cancer, vol. 89, n 1, p. 50-56, juill. 2015, doi: 10.1016/j.lungcan.2015.04.014.

11. H. Tekatli et al., " Outcomes of Hypofractionated High-Dose Radiotherapy in Poor-Risk Patients with "Ultracentral" Non-Small Cell Lung Cancer », Journal of Thoracic Oncology, vol. 11, n 7, p. 1081-1089, juill. 2016, doi: 10.1016/j.jtho.2016.03.008.

12. S. Raman et al., « Ultracentral Tumors Treated With Stereotactic Body Radiotherapy: SingleInstitution Experience », Clinical Lung Cancer, vol. 19, nº 5, p. e803-e810, sept. 2018, doi: 10.1016/j.cllc.2018.06.001.

13. D. H. Murrell, J. M. Laba, A. Erickson, B. Millman, D. A. Palma, et A. V. Louie, « Stereotactic ablative radiotherapy for ultra-central lung tumors: prioritize target coverage or organs at risk? », Radiation Oncology, vol. 13, nº 1, déc. 2018, doi: 10.1186/s13014-018-1001-6.

14. M. Loi et al., « Stereotactic Radiotherapy for Ultra-Central Lung Oligometastases in Non-Small-Cell Lung Cancer », Cancers, vol. 12, n 4, p. 885, avr. 2020, doi: 10.3390/cancers12040885. 
15. D. Yang et al., «Stereotactic ablative radiotherapy of $60 \mathrm{~Gy}$ in eight fractions is safe for ultracentral non-small cell lung cancer », Thoracic Cancer, vol. 11, n 3, p. 754-761, mars 2020, doi: 10.1111/1759-7714.13335.

16. R. D. Timmerman, «An Overview of Hypofractionation and Introduction to This Issue of Seminars in Radiation Oncology », Seminars in Radiation Oncology, vol. 18, $n^{\circ}$ 4, p. 215-222, oct. 2008, doi: 10.1016/j.semradonc.2008.04.001.

17. S. Adebahr et al., « LungTech, an EORTC Phase II trial of stereotactic body radiotherapy for centrally located lung tumours: a clinical perspective», The British Journal of Radiology, vol. 88, n 1051, p. 20150036, juill. 2015, doi: 10.1259/bjr.20150036.

18. K. N. B. Nguyen, D. J. Hause, J. Novak, A. M. Monjazeb, et M. E. Daly, « Tumor Control and Toxicity after SBRT for Ultracentral, Central, and Paramediastinal Lung Tumors », Practical Radiation Oncology, vol. 9, n² 2, p. e196-e202, mars 2019, doi: 10.1016/j.prro.2018.11.005.

19. Y. Cong et al., "Outcomes and toxicity of stereotactic body radiation therapy for advanced stage ultra-central non-small cell lung cancer », Thoracic Cancer, vol. 10, n 7, p. 1567-1575, juill. 2019, doi: 10.1111/1759-7714.13105.

20. C. Wang et al., «Analysis of Toxic Effects With Antiangiogenic Agents Plus Stereotactic Body Radiation in Ultracentral Lung Tumors », JAMA Oncology, vol. 5, nº 5, p. 737, mai 2019, doi: 10.1001/jamaoncol.2019.0205.

21. C. Wang et al., " Analysis of pneumonitis and esophageal injury after stereotactic body radiation therapy for ultra-central lung tumors », Lung Cancer, vol. 147, p. 45-48, sept. 2020, doi: 10.1016/j.lungcan.2020.07.009.

22. M. Duijm et al., « Predicting High-Grade Esophagus Toxicity After Treating Central Lung Tumors With Stereotactic Radiation Therapy Using a Normal Tissue Complication Probability Model », International Journal of Radiation Oncology ${ }^{\star}$ Biology ${ }^{\star}$ Physics, vol. 106, n 1 , p. 73-81, janv. 2020, doi: 10.1016/j.ijrobp.2019.08.059.

23. J. Y. Chang et al., " Clinical outcome and predictors of survival and pneumonitis after stereotactic ablative radiotherapy for stage I non-small cell lung cancer », Radiation Oncology, vol. 7, $\mathrm{n}^{0}$ 1, déc. 2012, doi: 10.1186/1748-717X-7-152.

24. S. L. Tucker et al., « Is there an impact of heart exposure on the incidence of radiation pneumonitis? Analysis of data from a large clinical cohort ", Acta Oncol, vol. 53, n 5, p. 590-596, mai 2014, doi: 10.3109/0284186X.2013.831185.

25. O. Y. Wong et al., « Survival Impact of Cardiac Dose Following Lung Stereotactic Body Radiotherapy ", Clinical Lung Cancer, vol. 19, n² 2, p. e241-e246, mars 2018, doi: 10.1016/j.cllc.2017.08.002.

26. H.-H. Wang et al., « Stereotactic radiation therapy for oligometastases or oligorecurrence within mediastinal lymph nodes », Oncotarget, vol. 7, n 14, p. 18135-18145, avr. 2016, doi: 10.18632/oncotarget.7636. 
27. N. P. Nguyen, L. Garland, J. Welsh, R. Hamilton, D. Cohen, et V. Vinh-Hung, « Can stereotactic fractionated radiation therapy become the standard of care for early stage non-small cell lung carcinoma », Cancer Treatment Reviews, vol. 34, nº 8, p. 719-727, déc. 2008, doi: 10.1016/j.ctrv.2008.06.001.

28. H. Onishi et al., « Hypofractionated stereotactic radiotherapy (HypoFXSRT) for stage I non-small cell lung cancer: updated results of 257 patients in a Japanese multi-institutional study », J Thorac Oncol, vol. 2, nº 7 Suppl 3, p. S94-100, juill. 2007, doi: 10.1097/JT0.0b013e318074de34.

29. H. Chen, J. M. Laba, S. Zayed, R. G. Boldt, D. A. Palma, et A. V. Louie, « Safety and Effectiveness of Stereotactic Ablative Radiotherapy for Ultra-Central Lung Lesions: A Systematic Review », Journal of Thoracic Oncology, vol. 14, n 8, p. 1332-1342, août 2019, doi: 10.1016/j.jtho.2019.04.018.

30. R. J. Klement et al., « Correlating Dose Variables with Local Tumor Control in Stereotactic Body Radiation Therapy for Early-Stage Non-Small Cell Lung Cancer: A Modeling Study on 1500 Individual Treatments », International Journal of Radiation Oncology, Biology, Physics, vol. 107, nº 3, p. 579-586, juill. 2020, doi: 10.1016/j.jijrobp.2020.03.005.

31. M. Giuliani et al., « SUNSET: Stereotactic Radiation for Ultracentral Non-Small-Cell Lung Cancer-A Safety and Efficacy Trial », Clinical Lung Cancer, vol. 19, n 4, p. e529-e532, juill. 2018, doi: 10.1016/j.cllc.2018.04.001.

\section{Tables}


Table 1

Patient and tumour characteristics

\begin{tabular}{|c|c|}
\hline Patient and tumour characteristics & Number of patients (\%) or median value (min-max) \\
\hline Age at SBRT (years) & $69(19-90)$ \\
\hline \multicolumn{2}{|l|}{ Gender } \\
\hline Female & $28(37.8 \%)$ \\
\hline Male & $46(62.2 \%)$ \\
\hline \multicolumn{2}{|l|}{ ECOG performance status } \\
\hline $0 / 1 / 2 / 3 / \mathrm{NA}$ & $20(27 \%) / 31(41.9 \%) / 7$ (9.5\%) / 1 (1.4\%) / 15 (20.3\%) \\
\hline Previous lung surgery & $20(27 \%)$ \\
\hline One lung only & $2(2.7 \%)$ \\
\hline \multicolumn{2}{|c|}{ Other thoracic radiation with <2 Gy overlap } \\
\hline Previous & $9(12.2 \%)$ \\
\hline Concurrent & $6(8.1 \%)$ \\
\hline \multicolumn{2}{|l|}{ Type of primary cancer } \\
\hline NSCLC & $37(50 \%)$ \\
\hline ADK / SCC / other histology & $21(28.4 \%) / 14$ (18.9\%) / 2 (2.7\%) \\
\hline No histology & $18(24.3 \%)$ \\
\hline Sarcoma & $7(9.5 \%)$ \\
\hline Colorectal cancer & $4(5.4 \%)$ \\
\hline Kidney cancer & $3(4.1 \%)$ \\
\hline Thyroid cancer & $2(2.7 \%)$ \\
\hline Breast cancer & $1(1.4 \%)$ \\
\hline Prostate cancer & $1(1.4 \%)$ \\
\hline Pleural mesothelioma & $1(1.4 \%)$ \\
\hline \multicolumn{2}{|l|}{ Stage at time of treatment } \\
\hline Localised disease & $39(52.7 \%)$ \\
\hline Metastatic disease & $30(40.5 \%)$ \\
\hline Localised relapse & $5(6.8 \%)$ \\
\hline
\end{tabular}




\begin{tabular}{ll} 
Parenchymal tumour & $67(90.5 \%)$ \\
\hline Lymph node & $6(8.1 \%)$ \\
\hline Pleural tumour & $1(1.4 \%)$
\end{tabular}

SBRT: stereotactic body radiotherapy; ECOG: eastern cooperative oncology group; NA: not applicable; NSCLC: non-small cell lung cancer; ADK: adenocarcinoma; SCC: squamous cell carcinoma 
Table 2

Treatment characteristics

\begin{tabular}{|c|c|}
\hline Treatment characteristics & Number of patients (\%) or median value (min-max) \\
\hline Planning, days & $10(5-25)$ \\
\hline \multicolumn{2}{|l|}{ Ultra-central organs at risk overlapped by PTV } \\
\hline Trachea & $10(13.5 \%)$ \\
\hline Right and left main bronchi & $12(16.2 \%)$ \\
\hline Intermediate bronchus and lobe bronchi & $25(33.8 \%)$ \\
\hline Oesophagus & $8(10.8 \%)$ \\
\hline Heart & $30(40.5 \%)$ \\
\hline Number of fractions & $5(5-10)$ \\
\hline 5 & $51(68.9 \%)$ \\
\hline 6 & $6(8.1 \%)$ \\
\hline 7 & $1(1.4 \%)$ \\
\hline 8 & $9(12.2 \%)$ \\
\hline 10 & $7(9.5 \%)$ \\
\hline Dose per fraction, Gy & $8(4.5-10)$ \\
\hline$\leq 6$ Gy & $18(24.3 \%)$ \\
\hline From 7 to $8 \mathrm{~Gy}$ & $23(31.1 \%)$ \\
\hline$\geq 9$ Gy & $33(44.6 \%)$ \\
\hline $\mathrm{BED}_{10}$ prescribed dose, Gy & $82(28-105)$ \\
\hline $\mathrm{BED}_{10}$ prescribed dose $\geq 100 \mathrm{~Gy}$ & $28(37.8 \%)$ \\
\hline $\mathrm{BED}_{10}$ prescribed dose $<100 \mathrm{~Gy}$ & $46(62.2 \%)$ \\
\hline Prescription isodose, \% & $80(78-95)$ \\
\hline $78-82 \%$ & $69(93.2 \%)$ \\
\hline $90-95 \%$ & $5(6.8 \%)$ \\
\hline GTV, mL & $18.3(1-108)$ \\
\hline PTV, mL & $51.6(6.6-243)$ \\
\hline
\end{tabular}

PTV: planning target volume; $B_{10}$ : biologically effective dose with $\alpha / \beta=10 ; G T V$ : Gross tumour volume 
Table 3

Dosimetry

\begin{tabular}{|c|c|}
\hline Dosimetric parameters & Median value (min-max) \\
\hline$G T V D_{\text {ave }}\left(B E D_{10}\right), G y$ & $99(54-139)$ \\
\hline GTV $D_{\text {med }}\left(B E D_{10}\right), G y$ & $99(53-140)$ \\
\hline$G T V D_{\min }\left(B E D_{10}\right), G y$ & $65(39-120)$ \\
\hline$G T V D_{\max }\left(B E D_{10}\right), G y$ & $112(59-151)$ \\
\hline $\mathrm{D}_{98 \%} \mathrm{PTV}\left(\mathrm{BED}_{10}\right), \mathrm{Gy}$ & $64(28-98)$ \\
\hline $\mathrm{D}_{1 \%}$ PTV $\left(\mathrm{BED}_{10}\right), \mathrm{Gy}$ & $110(58-149)$ \\
\hline $\mathrm{D}_{\text {ave }}$ PTV (between $\mathrm{D}_{1 \%}$ and $\left.\mathrm{D}_{98 \%}\right)\left(\mathrm{BED}_{10}\right)$, Gy & $86(51-121)$ \\
\hline $\mathrm{D}_{\text {ave }}$ PTV (between $\mathrm{D}_{1 \%}$ and prescribed dose) $\left(\mathrm{BED}_{10}\right)$, Gy & $96(50-126)$ \\
\hline PTV coverage, $\%$ & $87(40-100)$ \\
\hline Paddick conformity index & $0,72(0.1-0.89)$ \\
\hline$D_{\text {max }}$ trachea $(E Q D 23 / a=3)$, Gy & $8(0-155)$ \\
\hline$D_{\max }$ bronchi (EQD2 3/a=3), Gy & $65(0-188)$ \\
\hline$D_{\max }$ eosophagus (EQD2 3/a=3), Gy & $22(2-91)$ \\
\hline$D_{\max }$ heart $(E Q D 23 / a=3)$, Gy & $65(0-173)$ \\
\hline$D_{\text {ave }}$ homolateral lung (EQD2 3/a=3), Gy & $6(1-24)$ \\
\hline
\end{tabular}

GTV: gross tumour volume; $D$ : dose; $D_{\text {ave }}$ : average dose; $B D_{10}$ : biologically effective dose with $\alpha / \beta=10$; $D_{\text {med }}$ : median dose; $D_{\text {min }}$ : minimum dose; $D_{\text {max }}$ : maximum dose; $D_{98 \%}$ : dose received by $98 \%$ of PTV; PTV: planning target volume; $\mathrm{D}_{1 \%}$ : dose received by $1 \%$ of PTV; EQD2: 2 Gy per fraction equivalent dose 
Table 4

Acute toxicities

\begin{tabular}{|lcccccc|}
\hline Acute toxicities & \multicolumn{2}{c}{ Grade 1 } & \multicolumn{2}{c|}{ Grade 2 } & \multicolumn{2}{c|}{ Grade 3 } \\
\hline Anorexia & 1 & $1.4 \%$ & 0 & $0 \%$ & 0 & $0 \%$ \\
\hline Fatigue & 17 & $23.0 \%$ & 3 & $4.1 \%$ & 0 & $0 \%$ \\
\hline Lung toxicities & & & & & & \\
\hline Cough & 8 & $10.9 \%$ & 1 & $1.4 \%$ & 0 & $0 \%$ \\
\hline Dyspnea & 4 & $5.4 \%$ & 0 & $0 \%$ & 0 & $0 \%$ \\
\hline Hemoptysis & 1 & $1.4 \%$ & 0 & $0 \%$ & 0 & $0 \%$ \\
\hline Pneumonitis & 0 & $0 \%$ & 0 & $0 \%$ & 1 & $1.4 \%$ \\
\hline Oesophagitis & 1 & $1.4 \%$ & 2 & $2.7 \%$ & 1 & $1.4 \%$ \\
\hline
\end{tabular}

Table 5

Grade 3 acute toxicities

\begin{tabular}{|c|c|c|}
\hline Characteristics & Oesophagitis & Pneumonitis \\
\hline History & $\begin{array}{l}61 \text { years old, no previous radiotherapy } \\
\text { or thoracic surgery, no diabetes }\end{array}$ & $\begin{array}{l}83 \text { years old, no previous radiotherapy } \\
\text { or thoracic surgery, no diabetes }\end{array}$ \\
\hline $\begin{array}{l}\text { Irradiated } \\
\text { tumour }\end{array}$ & $\begin{array}{l}\text { Parenchymal primary tumour } \\
\text { (adenocarcinoma) }\end{array}$ & $\begin{array}{l}\text { Parenchymal primary tumour (no } \\
\text { histology) }\end{array}$ \\
\hline Prescribed dose & $\begin{array}{l}50 \text { Gy in } 5 \text { fractions on } 80 \% \text { isodose, } \\
\mathrm{BED}_{10}=100 \mathrm{~Gy}\end{array}$ & $\begin{array}{l}40 \text { Gy in } 5 \text { fractions on } 80 \% \text { isodose, } \\
\mathrm{BED}_{10}=72 \mathrm{~Gy}\end{array}$ \\
\hline OAR & Oesophagus & Heart \\
\hline Dosimetry & $D_{\max }$ oesophagus $=64,1 \mathrm{~Gy}$ & $\begin{array}{l}D_{\max } \text { heart }=86 \mathrm{~Gy} ; \mathrm{D}_{\text {ave }} \text { homolateral } \\
\text { lung }=4,6 \mathrm{~Gy}\end{array}$ \\
\hline PTV coverage & $94 \%$ & $92 \%$ \\
\hline $\begin{array}{l}\text { Paddick } \\
\text { conformity } \\
\text { index }\end{array}$ & 0.79 & 0.79 \\
\hline PTV, mL & 53.5 & 42.7 \\
\hline Planning, days & 11 & 7 \\
\hline $\begin{array}{l}\text { Time to grade } 3 \\
\text { toxicities, days }\end{array}$ & 11 & 42 \\
\hline
\end{tabular}


$B E D_{10}$ : biologically effective dose with $\alpha / \beta=10 ;$ OAR: organ at risk; $D$ : dose; $D_{\text {max }}$ : maximum dose; $D_{\text {ave }}$ : average dose; PTV: planning target volume; GTV: gross tumour volume

Figures

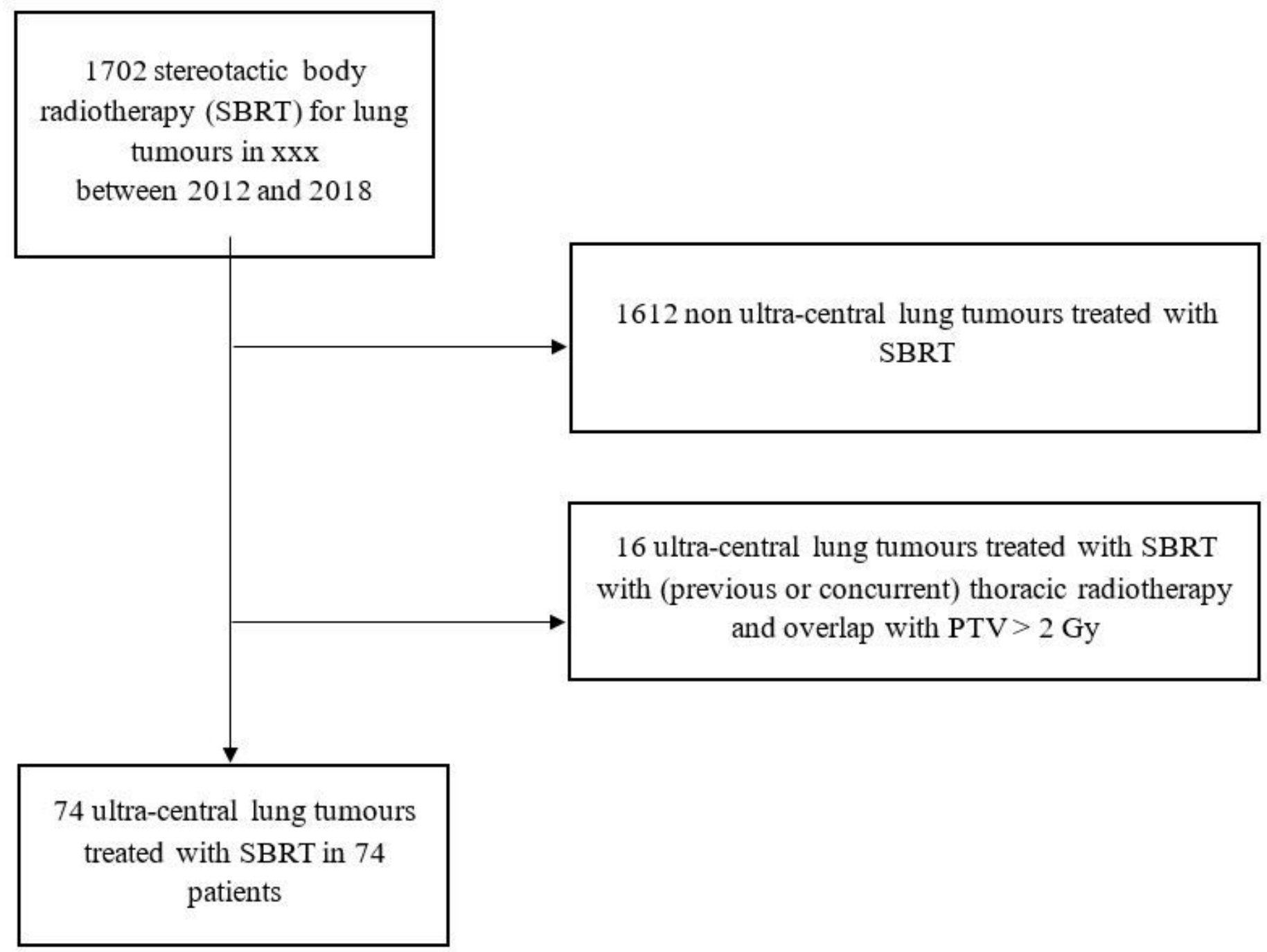

Figure 1

Flow chart 